\title{
BIJDRAGE TOT DE KENNIS VAN HET SAWUSCH DIALECT.
}

\author{
DOOR
}

DR. J. G. F. RIEDEL.

Omtrent het Sawusch dialect, dat door ongeveer vijfentwintig duizend zielen niet alleen op het eiland van dien naam, maar ook door de Sawusche kolonisten op Oost-Sumba wordt gebezigd, is voor zoover mij bekend nog niets gepubliceerd. Als proeve deel ik derhalve hier in het oorspronkelijke mede een uit den mond van den inlander opgeteekend kort verdicht verhaal, met nederlandsche vertaling en aanteekeningen.

Padara hewue rae era hedou ama amu do pano era pidu ana momone. Ri pidu ana momone nane pa helodo-helodo dodo pewoi hedou nga dohe wala midou aa ari rai ti hedou nga ana nga ina, je nadou pedonga pemuhu hedou nga do wala. Je rai ti helodo dai pa helodo amano tangadi ki worowu haada mipuhare era dodo i papidu ana momone nane, je kale rina nga hewue uku tatao pewoi paro. Amana ago pidu ata adju do made je ake pekebue ne helau-helau dje hewue ake do naiki, je na pehele pidu ana pe titu pahedape. Na pepue ana do kepai ta pepaku ne adju, je na dodo make ta paku, pidu ata adju nane era pedjedje helau-helau, pedutu ana do terora hari dodo make, je amana wië wari pa ana do wala-wala dai pa ana do pedakorai. Rai ana do dopidu hari-hari dodo makatape paku ne pidu ata adju, naboka nedari je paku ri na hehi-hehi ata dai peele. No lipa ro nepu nane pidu ata adju aleke pe paku. Ne ana-ana hami pa amana, do paku ama heata heata, jeri dje pedjedje pidu ata hari-hari dje doodu dai tado maka hapaku. Haku amana li pa ro kori-kori mu helodo-helodo era woi je daniade hedou donga hewala, donga woi je haada hari-hari midou aa ari dje rai dohewal dodo maka tatao wooapa pa mu, mi $\mathrm{mu}$ hari-hari dodo maka tapaku ne pidu ata adju, je mu hari-bari 
ta rubadara hedou pa dowala, dje ki mu hari-hari pedongga pebubudara haringa here pewale nge hedou rai do wala dongga manggi do hewala-wala tatao wo apa pa mu hedou pedutu dowala dai ta pehala nga manggi pamu do pidu ninami donga gapa do ngine ja ale pepaku do pidu ata adju. Po hekediki nahede ne pidu ana ale peranggi li pika rai ti ama anga, nadou ta mekae dara, rai ti worown haada do doi, je nadou ale pewoi je hari-hari hedou nga do wala pahedapa amana je peenga woi je daniade hedou do nga wala rai anga do erapa dida rae nade.

Vertaling. Er woonde in zekere negari een huisvader die zeven zonen had. Deze jongens leefden niet met elkander als broeders, (kinderen) van een vader en moeder, maar als vijanden, de een van den ander. De vader ziende dat de oneenigheid tusschen zijne zonen hoe langer hoe erger werd, bedacht een middel om hen tot rede te brengen. Hij nam zeven stuks drooge takken, bond deze bij elkander tot een bundel en liet zijne zonen voor zich komen. Aan zijn oudsten zoon den bundel ter hand stellende, liet hij hem deze in tweeën breken, hetzelfde deed hij bij de overigen tot en met den jongsten zoon. Toen de zevende zoon den bundel ook niet kon breken, nam hij deze, en na den bundel losgemaakt te hebben brak hij de takken den een na den ander. Gij ziet, zeide hij, dat de zeven takken nu gebroken zijn. Ja, antwoorden de zonen, gij hebt de takken een voor een gebroken, maar wij hebben getracht allen te gelijk te breken en dit is niet gelukt, omdat het niet mogelijk was. Daarop zeide de vader: wanneer gijlieden allen in vrede met elkander als broeders leeft, dan zal niemand een uwer kwaad kunnen doen gelijk gij den bundel niet hebt kunnen breken, omdat de een den ander steunt, maar wanneer gij in onderlinge vijandschap leeft, dan zal het een ieder gemakkelijk vallen $\mathrm{u}$ den een na den ander te benadeelen, totdat gij allen verloren zijt, gelijk ik zooeven de takken heb gebroken. De zonen, de rede van den vader hoorende, werden beschaamd over hun lakenswaardig gedrag, voor het aangezicht van den vader sloten zij vrede met elkander en bleven eensgezind, zoolang zij op aarde leefden.

Aanteekeningen. Padara, in. Hewue, een, gewoonlijk gebezigd als het Maleische لـو. Rae negari, oord. Ama amu, vader van het huis. Pano, bij hem, Momone, mannelijk. Helodo-helodo, altijd, immer. Pewoi, in vrede zijn, leven. Dohe wala, do wala, met den ander. 
Aari, broeders. Pemuhu, vijandschap. Tangadi, ngade, zien, bemerken. Worowu, gedrag, karakter. Mipuhare, alzoo. Uku, middel, knoop. Ata, stuk. Made, droog, verdord. Ake, vastbinden. Pekebue, bijeenbrengen, verzamelen. Helau-helau, te zamen. Naiki, klein. Pehele, roepen. Titu, staan. Pahedape, (staan) voor *iemand. Pepu, laten, zenden. Kepai, oudste. Paku, breken, Pedjedje, laagsgewijs, op of bij elkander. Terora, midden, die tusschen is. Wari, jongste kind. Hari-har, allen. Boka, los, open maken. Dari, touw, band. Hehihehi, een voor een. Peele, afgeloopen, ele, gedaan. Nepu, nu. Hami, antwoorden. Heata-heata, stuk voor stuk. Jeri, maar. Doodu, hard, sterk. Dohewal, niemand, geen sterveling. Tatao, tao, doen. Woapa, kwaad. Rubadara, helpen. Here, twist, oneenigheid. Manggi, gemak. Pehala, vernield. Ngine, zooeven. Hekediki, terstond. Ranggi, hooren, vernemen. Pika, woorden. Dara, schaamte. Mekae dara, schaamte gevoelen. $R a$, bloed in het aangezicht voelen. Erapa, leven. Dida, op. 